\title{
Cuidado em saúde no território na interface entre Saúde Mental e Estratégia de da Saúde Família ${ }^{\star}$
}

\author{
Solange Santana Vieira, I Claudia Abbês Baêta Neves ${ }^{I I, \star \star ~}$ \\ ${ }^{I}$ Faculdade Salesiana Maria Auxiliadora, Macaé, RJ, Brasil \\ ${ }^{I I}$ Universidade Federal Fluminense, Niterói, RJ, Brasil
}

\begin{abstract}
Resumo
O artigo reflete sobre a complexidade do cuidado em saúde no território na intercessão entre a Saúde Mental e a Atenção Básica. Para tanto, problematiza o conceito de território, a partir das contribuições da geografia e da filosofia, afirmando-o em seu caráter processual e de experimentação no acompanhamento de processos existenciais que o materializam. Esta discussão permite-nos experimentar uma problematização da prática clínica e nos convoca à construção de uma prática ética de cultivo da dimensão pública de todo processo de saúde. Público, aqui pensado na inseparabilidade de três processos de produção: produção de saúde, subjetividade e territórios existenciais.
\end{abstract}

Palavras-chave: Saúde Mental; Atenção Primária à Saúde; território; cuidado em saúde.

\section{Health care in the territory at the interface between Mental Health and Family Health Strategy}

\begin{abstract}
This article reflects on health care complexity in the territory of the intersection between Mental Health and Primary Care. For both, discusses the concept of territory, from the contributions of geography and philosophy, stating it in its procedural nature and experimentation in monitoring existential processes that materialize it. This discussion allows us to experience a questioning of clinical practice itself and summon us to the construction of an ethical practice of cultivating the public dimension in the entire health care process. The concept of public is analyzed considering the inseparability of three production processes: production of health, subjectivity and existential territories.
\end{abstract}

Keywords: Mental Health; Primary Care; territory; health care.

\section{Introdução}

Neste artigo objetivamos problematizar os processos e práticas de produção de cuidado no território na interface entre Saúde Mental e Estratégia de Saúde da Família. Refletirmos sobre a importância da dimensão intercessora (DELEUZE, 1992) com/nas práticas de cuidado no território nos permite entender a experiência de deslocamento, de trânsito e criação que somos, paradoxalmente, convocados a "habitar" quando lidamos, no plano relacional, com o que se passa "entre": no encontro Saúde Mental e Atenção Básica. É nesta dimensão intercessora que o pensamento amplia e desnaturaliza o mero dado, produzindo outras inferências e interferências que, em ato, nos fazem atentar para o encontro entre Reforma Psiquiátrica e Reforma Sanitária.

Esta interface é aqui pensada a partir de nossa experiência profissional como psicólogas no campo da formação, da pesquisa e do trabalho em saúde, assim como de registros oriundos de uma pesquisa cartográfica que foi realizada pela primeira autora, em 2008 e 2009, na rede de saúde do Município de Macaé (RJ) junto a Equipes de Saúde da Família (VIEIRA, 2009).

\footnotetext{
^Este texto é inédito e faz parte da dissertação de mestrado da primeira autora, defendida em 2009, sob orientação da segunda autora. A primeira autora fo bolsista da Coordenação de Aperfeiçoamento de Pessoal de Nível Superior (Capes). A pesquisa foi aprovada pelo Comitê de Ética em Pesquisa da Faculdade de Medicina/Hospital Universitário Antônio Pedro (CEP CMM/HUAP), sob o protocolo 087/08. Declaramos que não houve conflito de interesses na sob o protocolo $087 / 08$. Dec
concepção deste trabalho.

$\star \star$ Endereço para correspondência: Universidade Federal Fluminense, Instituto de Ciências Humanas e Filosofia. Campus do Gragoatá, s/n $\mathrm{n}^{\circ}$ - Bloco O, sala 210. São Domingos. Niteroi, RJ - Brasil. CEP: 24210-201. E-mail: vieirapsi@ hotmail.com, abbes@luma.ind.br
}

A metodologia de pesquisa utilizada foi a cartografia, que marca uma afirmação da produção da pesquisa como método processual criado em sintonia com o domínio igualmente processual que ele abarca. Neste sentido, implica menos a apreensão da realidade como matéria de desvelamento ou cognição, e mais a afirmação da realidade em sua potência de abertura de sentidos e invenção.

A cartografia foi realizada na rede de saúde do Município de Macaé no período de 07 meses fazendo-se junto a uma equipe de Saúde Mental e uma equipe da Estratégia de Saúde da Família com as quais participamos de um grande número de atividades que se pretendem construtoras desta articulação, tais como: visitas domiciliares, capacitações, oficinas terapêuticas e interconsultas. Destacamos também como parte integrante desta pesquisa, os acontecimentos que marcam o ir e vir no território durante as visitas domiciliares, as festas e confraternizações, o bate-papo nos cafezinhos, as conversas na recepção, no corredor ou salas do módulo do PSF e nas reflexões que fazíamos nas chegadas e partidas da comunidade que as equipes atuavam.

As novas diretrizes produzidas na área da saúde, nos últimos anos, inclusive com recomendação da Organização Mundial de Saúde (OMS), têm convocado, especialmente, os profissionais que atuam na atenção primária e outras áreas afins, a intervir nos processos de reabilitação das pessoas em sofrimento, quer sejam eles: por sofri${ }^{1}$ Também fez parte desta cartografia a participação da primeira pesquisadora, 01
vez por mês, na reunião de equipe da saúde mental juntamente com os demais
integrantes que compõem a Saúde Mental na Atenção Básica e que trabalham em outras comunidades. 
mento mental, pelo uso de drogas de modo suicida, por angústias, violências ou graves opressões (LANCETTI; AMARANTE, 2006). Esta convocação não é uma novidade dos tempos atuais, mas fruto de intensos debates, reflexões e interesses ético-político-econômicos diversos no campo da saúde internacional e da Reforma Sanitária Brasileira, desde o final da década de 70 do século passado.

No que pese a importância do olhar e tecnologia do especialista em saúde mental, percebe-se que determinadas necessidades expressas por parte significativa da população encaminhada não podem ser satisfeitas com base apenas em tecnologias utilizadas por essa ou aquela especialidade. Em muitos casos, o empreendimento de longos processos psicoterápicos e a administração de psicotrópicos se mostram insuficientes como únicas respostas. O melhor acompanhamento de muitas dessas demandas se faz na integralidade e esforços conjuntos dos profissionais envolvidos, mobilizando outros dispositivos da rede, recursos da própria comunidade - materiais e subjetivos - a serem pactuados com o usuário ou rede social em questão (CAMPOS, F.; NASCIMENTO, 2007; FIGUEIREDO, 2006).

Dedicarmo-nos à reflexão desta questão tem para nós, trabalhadores da saúde, extrema relevância, pois sabemos que é nesta dedicação que construímos nossas práticas, que emprestamos outros sentidos ao nosso contemporâneo. É neste cuidar do que fazemos juntos que podemos construir um entendimento de nossa prática tendo maior clareza da complexidade e relevância de trabalharmos nesta intercessão como um modo de fazer o projeto de democratização institucional que está na base do SUS (VIEIRA, 2009).

A complexidade que envolve este cuidar se atualiza na "lida" cotidiana com uma miríade de interferências e processos paradoxais que atravessam as ações cujo foco de cuidado é "o território [...] e a vida que o anima" (SANTOS, 1996, p. 26). Nesta lida, nos vemos convocados ao cultivo de um modo de fazer os processos de produção de saúde que desestabilize os limites identitários das disciplinas/saberes produzindo um atravessamento dos mesmos. Pois, não se trata de uma dimensão apenas técnica, mas acima de tudo ético-política (NEVES, 2011).

É nesta direção que a complexidade é, aqui, afirmada como matéria constituinte das práticas que se voltam para o enfrentamento dos desafios e tensionamentos cotidianos em meio aos quais se tecem as políticas de gestão, produção e promoção em saúde no território. Assim, os desafios a serem enfrentados não são signos de impedimentos, mas a matéria viva em meio a qual se produz/ promove o trabalho em saúde na interface Saúde Mental e Atenção Básica.

\section{Desafios na articulação entre Saúde Mental e Atenção Básica}

Paim (2012) ao discutir sobre a emergência da Atenção Primária à Saúde (APS) e seus usos políticos na direcionalidade das intervenções em saúde, chama a atenção para o fato de após mais de 30 anos da Conferência de Alma-Ata a proposta da APS ainda protagonizar e des- pertar intensos debates e reflexões quanto a seus objetivos e funções na organização/coordenação da assistência e dos sistemas de saúde.

Esta discussão tem assumido vários sentidos e servido a diferentes interesses político-econômicos no campo da saúde desde a Conferência, em 1978, ocasião da divulgação oficial e conceitual da noção de atenção primária à saúde, acolhida e conclamada pela Organização Mundial de Saúde (OMS) como solução para os países proporcionarem atenção ao conjunto da população em seu viés de extensividade (MOTA; SCHRAIBER, 2011).

As reformas setoriais preconizadas e incentivadas por organismos internacionais (OMS, Organização Pan Americana de Saúde - OPAS, Banco Mundial) no que diz respeito à atenção primária guardam uma ambiguidade discursiva acerca da função dessa modalidade assistencial como expansão de cobertura e de uma assistência "simplificada (restrita) para pobres". Esta ambiguidade discursiva diz respeito não apenas as funções da APS na organização de modelos de gestão (tecnológicos e/ou assistenciais) nos sistemas de saúde, mas, se alia aos ditames do capital e ao poder político dos Estados configurados a partir de uma ordem mundial neoliberal, restritiva aos gastos sociais, que usam a saúde na intervenção sobre a pobreza, na acumulação do capital e na contenção das tensões sociais.

Os efeitos políticos e as inflexões conceituais produzidas em diferentes experiências da APS, no Brasil e demais países da América Latina desde a década de 70 do século passado, não podem ser negligenciados e a APS contemporânea precisa ser problematizada, segundo Paim (2012, p. 343), a luz "de sua matriz político-ideológica", qual seja:

[...] construída nos anos 1960 do século XX e associava-se à 'guerra contra a pobreza' das administrações Kennedy e Jonhson quando floresceram os programas de medicina comunitária para aliviar tensões sociais acumuladas pelas lutas dos negros americanos contra o racismo e pelos direitos civis. Essas iniciativas foram difundidas posteriormente através de fundações americanas como a Kellog e a Rockefeller, além de organismos internacionais e da Igreja, para diversos países.

No contexto latino-americano a APS ganhou historicamente diferentes sentidos, desde ser entendida como primeiro nível de atenção, como atenção primária seletiva com cesta restrita de ações, como estratégia para organizar o sistema de saúde ou até mesmo para impactar nos determinantes sociais (MOTA; SCHRAIBER, 2011).

No Brasil, a partir de diferentes experiências vinculadas a programas experimentais de saúde comunitária (MOTA; SCHRAIBER, 2011) no âmbito da Reforma Sanitária Brasileira, optou-se, nas décadas de 80 e 90, por uma mudança de denominação da APS para Atenção Básica (AB) e de "estratégia" para o Programa de Saúde da Família (PSF), rechaçando-se a ideia da atenção primária como assistência simplificada e de baixo custo para pobres. Visava-se com isto afirmar a AB numa perspectiva de coordenação do sistema de saúde objetivando garantir maior abrangência, integração e integralidade. Segundo 
Mota e Schraiber (2011) no final dos anos 90, esta perspectiva de coordenação cresce pari passu à expansão da Estratégia Saúde da Família (ESF), que, ao final dos anos 1990, foi assumida pelo governo brasileiro como proposta para reorganização do sistema de saúde na perspectiva da implementação de uma APS abrangente.

As experiências brasileiras na atenção básica e as discussões daí decorrentes têm confirmado, ainda que não em sua totalidade, a $\mathrm{AB}$ com potencial de coordenação dos cuidados entre os distintos níveis assistenciais, influindo nos determinantes sociais mediante trabalho intersetorial.

Ainda que a marca APS- atenção primitiva de saúde, conforme nomenclatura crítica cunhada por Testa (1992),- ainda esteja presente em muitos direcionamentos das políticas de saúde no Brasil, as experiências brasileiras na $\mathrm{AB}$ produziram novos problemas nas pautas internacionais, regionais e locais de saúde fazendo comparecer a atenção básica como um modelo de gestão que possibilita "relacionar os problemas e necessidades em saúde dos conjuntos sociais que vivem em espaços geográficos delimitados com os conhecimentos e recursos, institucionais e comunitários, de tal modo que seja possível definir prioridades" (PAIM, 2002, p. 330).

O tema da rede básica e, sobretudo, do território tem sido colocado como ponto estratégico para a constituição de novas práticas no campo da saúde que operem uma ruptura com certo modelo assistencial e tecnológico de conhecimento que produz tanto um modelo assistencial médico hegemônico, quanto um modo de organização social voltado para o conceito de doença.

Nesta direção, a atenção básica em sua aliança com os movimentos sociais pode ser vista como importante espaço agonístico de reflexão crítica e de luta radical na construção de uma saúde integral, universal e pública, distante da marca histórica de fragmentação da APS.

A experimentação da Estratégia de Saúde da Família no Brasil, em mais de vinte anos, tem possibilitado importantes avanços do ponto de vista da ampliação do acesso, qualificação do cuidado, reconfiguração das demandas por serviços e dos modos de produzir e promover cuidado em saúde no território. Entretanto, nos vemos ainda muito distantes de termos a atenção básica como ethos na estratégia de (re)organização da rede de cuidados, funções e ações no sistema de saúde (PASCHE, 2010). A baixa cobertura e eficácia da rede de atenção básica, o baixo grau de articulação entre os diferentes níveis de atenção e entre as políticas de saúde, acrescidos da insuficiência dos financiamentos e da ausência de investimentos numa política de pessoal que atue na desprecarização vigente das formas de contratação e dos regimes de trabalho, persiste e compõe os desafios do trabalho na atenção básica (CAMPOS, G., 1997; PASCHE, 2010).

Um monitoramento realizado pelo Ministério da Saúde em 2001 e 2002 para avaliação da Estratégia de Saúde da Família em todo o país, a discussão quanto à elaboração de uma proposta de ação conjunta tendo como base a inserção da saúde mental na atenção básica tornou-se premente, visto que, $56 \%$ das equipes de saúde da família referiram realizar "alguma ação de saúde mental". ${ }^{2} \mathrm{O}$ trabalho efetivo no território tem enunciado diversas formas de sofrimento, desassistência e processos que transformam as diferenças em desigualdade e exclusão social. A incorporação das dimensões subjetiva e social na prática clínica das equipes da atenção básica, tendo em vista, o modus operandis ${ }^{3}$ de trabalho da Estratégia de Saúde da Família faz com que os profissionais da Saúde da Família se deparem cotidianamente com problemas de saúde mental.

Entendemos que há uma dimensão fértil e produtiva na interface Saúde Mental e Atenção Básica, sobretudo, quando temos a possibilidade de experimentar essa articulação em suas interferências e ressonâncias no campo da saúde. Se por um lado, temos demarcado nos princípios e diretrizes que oxigenam o movimento da Reforma Psiquiátrica a busca por uma desinstitucionalização do cuidado que opere, primordialmente, uma ruptura da cultura da tutela institucional e da lógica manicomial em nossas práticas cotidianas, também percebemos, por outro lado, o movimento da Reforma Sanitária que têm privilegiado no campo da atenção básica, em algumas experiências com a Estratégia de Saúde da Família (ESF), a sustentação e consolidação dos princípios do Sistema Único de Saúde (SUS).

Percebemos que esta interface se marca fortemente nas iniciativas de se pensar a produção de práticas de saúde mediante a construção de uma rede de cuidados de base territorial, postulada tanto pela própria definição dos serviços substitutivos da Reforma Psiquiátrica quanto pela Reforma Sanitária em seus princípios norteadores do SUS e sua efetividade na Atenção Básica (CAMPOS, G.; GUERRERO, 2010; LANCETTI, 2006).

A construção de um plano comum, que conecta diferentes atores no processo de produção de saúde, nos dá o tom de como se implanta efetivamente a ideia de "único" encontrada no SUS. Processo que se fez na e com as reverberações do encontro entre as reformas: psiquiátrica e sanitária. Com a saúde mental aprendíamos que o modo de se operar mudanças nos processos de produção de saúde exigia também mudanças nos processos de subjetivação. Aprendíamos também que é a transformação de sujeitos concretos em sintonia com as mudanças das próprias práticas de saúde que dá cheiro, cor e vida aos princípios do SUS quando encarnados na experiência concreta do fazer (BARROS; PASSOS, 2005).

\footnotetext{
${ }^{2}$ Levantamento do departamento de Atenção Básica, apresentado em Seminário Internacional sobre Saúde Mental na Atenção Primária - Opas/MS/Universidade de Harvard/UFRJ, abril de 2002.

${ }^{3}$ Para a ESF tem sido a possibilidade de um novo modo de operar o trabalho em saúde, uma inversão da lógica de cuidados - menos técnico e mais relacional tanto entre equipe-usuário como entre equipe-equipe. As equipes da Estratégia de Saúde da Família (ESF) são responsáveis pelo acompanhamento de um número definido de famílias, localizadas em uma área geográfica delimitada, atuando com ações de promoção da saúde, prevenção, recuperação, reabilitação de doenças e agravos mais frequentes, e na manutenção da saúde desta comunidade. Mediante a adstrição de clientela, as equipes de Saúde da Família estabelecem vínculo com a população, possibilitando o compromisso e a corresponsabilidade destes profissionais com os usuários e a comunidade. Seu desafio é o de ampliar suas fronteiras de atuação visando uma maior resolubilidade da atenção, onde a Saúde da Família é compreendida como a estratégia principal para mudança deste modelo, que deverá sempre se integrar a todo o contexto de reorganização do sistema de saúde.
} 
Sabemos que as transformações esperadas com a reforma sanitária, a institucionalização do SUS, a criação de equipes de saúde da família e outros arranjos/ dispositivos, não pressupõem uma mudança automática nas práticas de cuidado em saúde.

O processo de transformação cultural do lugar de desvalor que a loucura ocupa no imaginário social requer o envolvimento, a prática conjunta como meio indispensável de conhecer e comunicar de forma não abstrata, para encontrar outras formas de compreensão da loucura. A potencialização e a "reconversão de recursos" (NICÁCIO; KINKER, 1996) materiais, humanos e sociais para a criação de frentes de trabalho e ampliação da contratualidade social, e não para a exclusão e cronificação dos sujeitos, foi uma das estratégias centrais para fazer operar a desinstitucionalização das instituições.

Na prática, a implementação de novas políticas de saúde se produz, paradoxalmente, de forma contínua e desviante nos processos cotidianos de gestão/trabalho/ cuidado em saúde, e requerem o uso de uma tecnologia bastante complexa e "porosa" aos tensionamentos advindos da variedade e singularidade de situações com as quais que se depara. A produção do próprio território sanitário, em sua complexa variedade de determinantes e funcionamentos híbridos, pré e/ou pós-SUS, envolvem, produzem e tensionam os processos de gestão, produção e promoção em saúde instituídos, demandando dos diferentes sujeitos envolvidos nestes processos o exercício de uma prática inventiva que implica abertura e atenção aos modos singulares de vida/trabalho que movimentam e se forjam no território.

Segundo Lancetti (2006) a práxis operada no território evidencia-se por sua complexidade e oposição à simplificação que faz funcionar um manicômio e tem significado uma estratégica radical de desinstitucionalização para as ações da saúde mental. Percebemos também que esta complexidade se estende às equipes da Estratégia de Saúde da Família e seus modos de operar no/com o território quando convocadas em seu fazer a uma inversão da lógica de cuidados - menos técnico e mais relacional - tanto entre equipe-usuário/comunidade como entre equipe-equipe.

Nesta intercessão Saúde Mental e Atenção Básica, temos potencializado não somente a produção de saúde e construção de redes de cuidado integral, mas também, um processo de diferenciação no interior das próprias práticas de saúde. Trabalhar, pois com esta interface torna-se fundamental para a reorganização da atenção à saúde quando, também se faz urgente em nossa realidade a ruptura com dicotomias tais como saúde/saúde mental, exigindo-nos uma operação de transversalização de nossas práticas. Este desafio implica-nos, necessariamente, em ultrapassar as fronteiras, muitas vezes rígidas, dos diferentes núcleos de saber/poder que se ocupam da produção da vida fomentando em nosso dia a dia um processo contínuo de contratação e pactuação que só pode se efetivar a partir do aquecimento das redes e fortalecimento

Fractal, Rev. Psicol., v. 29 - n. 1, p. 24-33, 2017 dos coletivos garantindo o caráter questionador das verticalidades pelas quais estamos, na saúde, sempre em risco de nos ver capturados (BARROS; PASSOS, 2004).

Segundo Guattari (1981) a transversalidade constitui-se pelo grau de abertura que garante às práticas a possibilidade de diferenciação ou invenção, a partir de uma tomada de posição que faz dos vários atores sujeitos do processo de produção da realidade em que estão envolvidos. Aumentar os graus de transversalidade é superar a organização do campo assentada em códigos de comunicação e de trocas circulantes nos eixos da verticalidade e horizontalidade: um eixo vertical que hierarquiza os gestores, trabalhadores e usuários e um eixo horizontal que cria comunicações por estames/corporações. Ampliar o grau de transversalidade é produzir uma comunicação multivetorializada construída na intercessão dos eixos vertical e horizontal. Esta operação nos convoca a um outro modo de operar ${ }^{4}$ sobre/com as práticas, afirmando mais a dimensão processual de nosso fazer em saúde do que as formas. Neste sentido a operação de transversalização impõe-nos um processo de desestabilização inclusive daquilo que até então era nomeado como o campo da clínica.

Falarmos deste processo contínuo de pactuação na construção de práticas de cuidado no território implica-nos, sobretudo, em entendermos que nosso fazer em saúde se dá na inseparabilidade dos modos pelos quais construíamos nossa existência. Afirmamos aqui, muito mais a dimensão processual de nossas práticas e nossos modos de subjetivação, apostando na necessidade de indagarmos na intercessão Saúde Mental e Atenção Básica, o que temos entendido como território.

\section{Do Território e sua Ambiência}

No campo da atenção básica, a produção de um certo mapa do território sanitário utilizado como referencial para a estruturação da Estratégia de Saúde da Família têm sido marcado pela territorialização e adscrição da população a uma área de abrangência definida. Há nesta adscrição a recomendação de que uma equipe da Estratégia de Saúde da Família seja responsável pelo acompanhamento de, no máximo 4.500 pessoas. A produção de uma localização do espaço territorial que delimita a área de responsabilização de uma determinada equipe torna-se o lócus operacional do programa. Com a adscrição de 600 a 1.000 famílias à uma equipe de Saúde da Família preconiza-se como diretriz para este trabalho a longitudinalidade entendida como o acompanhamento das famílias ao longo do tempo independente da presença de patologia articulando assim a ideia de vínculo que tem como princípio a constituição de referências dos usuários para com os profissionais responsáveis pela sua área. Uma outra diretriz norteadora do trabalho no território

\footnotetext{
${ }^{4} \mathrm{Um}$ modo de fazer operar que produza a saída do circuito psiquiátrico foi pensado com a multiplicação de parceiros/atores envolvidos nestes projetos, haja vista, a participação de inúmeras outras pessoas como instrutores, clientes, gerentes, etc. E também, a busca de agenciamentos com atores cujo interesse comum por realizar intervenções urbanas e culturais na cidade eram articulados a um conjunto de ações (políticas públicas, associações não-governamentais e cidadãos).
} 
sanitário é constituída pelo planejamento ascendente que tem como proposta definir as ações de saúde a partir das necessidades identificadas no território vivo.

Mas o que entendemos como mapa? Como a partir dele podemos pensar a produção de um território?

Girardi (2006) nos indica que no dicionário cartográfico do Instituto Brasileiro de Geografia e Estatística (IBGE), o mapa é definido como uma representação gráfica das características naturais e artificiais, terrestres ou subterrâneas, ou ainda das características de outro planeta, feita geralmente numa superfície plana e em determinada escala. Nesta definição, os acidentes são representados dentro da mais rigorosa localização possível, relacionados, em geral, a um sistema de referência de coordenadas. Podemos aqui perceber uma necessidade de representação do espaço que busca, por muitos momentos, uma localização. Isto nos faz pensar que há, na preocupação de muitos que trabalham com a noção de território, uma pergunta pelo lugar.

Para a autora transformou-se lugar comum na geografia a expressão: "mapa é a representação do espaço" (GIRARDI, 2006, p. 65). Cabe aqui, questionarmos certo entendimento do mapa àqueles que o tomam como figura estática pressupondo-o capaz de representar uma realidade pré-existente. Isto nos exige pensar em como construímos os mapas bem como o uso que fazemos deles. Por hora, podemos pensar que certo traçado do mapa nos permite constituir contornos, limites territoriais que nos sirvam como referência, como guia. Ter um mapa significaria aqui, ter visibilidade do território e, portanto, 'segurança' no trânsito por esse território. Aqui, uma outra questão nos parece ser produzida nas tentativas de definição do território que não se faz somente por uma pergunta pelo lugar, mas também a de como transitar no território. Se podemos falar que vivemos na experiência de construção de mapas-territórios uma experiência de 'localização' já podemos dizer que aqui também se faz presente uma experiência de trânsito, de movimento.

O geógrafo Milton Santos (2008) nos ajuda a produzir algumas reflexões até mesmo dentro do campo das ciências geográficas, quando questiona as definições clássicas da geografia que entendem o espaço como resultado de uma interação entre o homem e a natureza bruta e, até mesmo, o mapa como uma representação estática do território. Em seu livro Metamorfoses do espaço habitado, o autor marca a importância de considerarmos os três modos pelos quais o espaço tem sido conceitualizado.

Em primeiro lugar, o espaço pode ser visto num sentido absoluto, como uma coisa em si, com uma existência específica, determinada de maneira única. [...] identificado mediante um quadro de referências convencional; especialmente nas latitudes e as longitudes. Em segundo lugar, há o espaço relativo, que põe em relevo as relações entre os objetos e que existe somente pelo fato de esses objetos existirem e estarem em relação uns com os outros. Assim, se tivermos três localidades A, B, C, estando os dois primeiros fisicamente próximos, ao passo que $\mathrm{C}$ está longe mas dispõe de melhores meios de transporte para A, é possível dizer, em termos relativos espaciais, que as localidades A e C estão mais próximas entre si do que A e B. Em terceiro lugar, há o espaço relacional, onde o espaço é percebido como conteúdo e representando no interior de si mesmo outros tipos de relação que existem entre objetos (SANTOS, 2008, p. 38. grifo nosso).

O autor evidencia uma aposta no entendimento da noção de território como espaço relacional quando afirma que o espaço não é algo em si, mas "um conjunto indissociável, de que participam, de um lado, certo arranjo de objetos geográficos, objetos naturais e objetos sociais, e, de outro, a vida que os preenche e os anima, ou seja, a sociedade em movimento (SANTOS, 2008, p. 27-28).

Entendemos o sentido precioso das contribuições deste autor para o nosso estudo, pois embora saibamos da importância da dimensão espacial concreta para pensarmos o conceito de território, também sabemos que ela não se sustenta por si própria.

Haesbaert (2007) nos chama atenção para a dupla conotação - material e simbólica - com a qual o território nasce desde a sua origem. Etimologicamente aproxima-se tanto de terra-territorium quanto de terreo-territor, portando, pois o sentido de dominação (jurídico-politica) da terra e também o de terror e medo, principalmente daqueles que ficam alijados da terra. Percebemos com este autor que o território em sua acepção está relacionado com o poder, mas não estritamente no sentido tradicional e mais explícito de 'poder político' ligado à dominação. Relaciona-se também ao poder no sentido simbólico de apropriação que para além do significado de posse, comporta também um sentido de pertencimento.

Portanto, todo território é, ao mesmo tempo e obrigatoriamente, em diferentes combinações, funcional e simbólico, pois as relações de poder têm no espaço um componente indissociável tanto na realização de "funções" quanto na produção de "significados" (HAESBAERT, 2007, p. 23).

Tomamos, então, como pista que para pensarmos a produção do cuidado no território na interface Saúde Mental e Atenção Básica, é necessário, antes de tudo, considerarmos a maneira como estamos entendendo o território que a saúde intervém. Este, não se reduz a uma região administrativa - visto termos mencionado ser o campo de ação da Atenção Básica constituído pelo traçado de um mapa sanitário com contornos geográficos ligados pela adscrição de um conjunto populacional a uma determinada equipe de trabalhadores. Entendemos ser esse território um ambiente vivo, que se por um lado possui uma dimensão territorializada que dá sua forma como: uma localização geográfica, um perfil populacional entremeado por fatores socioculturais; este território define-se, sobretudo, como vivo por portar uma dimensão que não é objetiva, mas puro processo de expressão evidenciando seu caráter processual e qualitativo (ALVAREZ; PASSOS, 2009). É, portanto, esta dimensão viva, processual e qualitativa que faz do território com e no qual operamos no campo da saúde um território existencial.

As contribuições de Guattari (1992) para pensarmos o conceito de território existencial nos são preciosas, pois com ele compreendemos que este não se refere a um ter- 
ritório como um ponto em um mapa, estático e já delimitado em si. Para além de uma delimitação espacial, um território existencial se define a partir de uma localização espacial que é configurada no tempo, sendo, pois, uma localização espaço-temporal. Sua constituição é de um território em processo, em constante processo de feitura.

A ideia de território existencial nos é cara, primeiramente, para pensar a intervenção, pois, entender sujeitos, populações e regiões como territórios existenciais nos traz a necessidade de considerar que não estamos somente intervindo junto a figuras determinadas. Estamos intervindo também junto a um processo de formação, uma dimensão não objetiva da realidade, o que torna mais complexa suas figuras, já que estas estão existindo em uma certa relação entre elementos objetivos e elementos não objetivos, não identificáveis, e que, toda essa complexidade está em constante mutação. [...] Se buscarmos deslocar o olhar de nossa intervenção, ao considerar os territórios existenciais, o que temos como foco são, antes dos sujeitos, paisagens subjetivas - todo um clima, um ambiente, que não são passiveis de serem reduzidos a sujeitos já determinados (MACERATA; SOARES; RAMOS, 2014, p. 922-923).

$\mathrm{O}$ caráter processual dos territórios existenciais nos faz pensar, sobretudo, na produção de uma outra territorialidade construída nas relações, nos indagando sobre o modo como habitamos o território e como, de fato, o produzimos.

Perlongher (1993, p. 54) nos sinaliza que essa territorialidade é, em seu modo de operar, "itinerante", e privilegia "os espaços intermediários da existência social, percursos, trajetórias, devires". Pois, segundo o autor, operar no território atento à sua dimensão itinerante é não sucumbir a uma fixitude monótona dos trajetos entendendo que "ainda quando se transite entre pontos; esses pontos são consequência dos trajetos" (PERLONGHER, 1993, p. 56).

Percebemos aqui, uma experiência itinerante vivida com/nos traçados dos territórios, muito próxima do que chamamos de prática cartográfica. Embora tomemos o termo cartografia emprestado da ciência geográfica, operamos nele uma inflexão com a ajuda de alguns autores. ${ }^{5}$ Diferentemente de um geógrafo que se interessa pelas formações estáveis e pela produção de mapas topográficos, o cartógrafo está comprometido em acompanhar a produção de territórios existenciais seus contornos e arranjos, tendo em vista que seus movimentos são sempre provisórios e estão sempre em transformação. Afirmamos a cartografia como

[...] um desenho que acompanha e se faz ao mesmo tempo que os movimentos de transformação da paisagem. Paisagens psicossociais também são cartografáveis. A cartografia, nesse caso, acompanha e se faz ao mesmo tempo que o desmanchamento de certos mundos - sua perda de sentido - e a formação de outros: mundos que se criam para expressar afetos contemporâneos, em relação aos quais os univer-

${ }^{5}$ Esta inflexão é operada por Deleuze e Guattari (1995) e Guattari e Rolnik (2005) e com ela afirmamos uma certa direção metodológica que coloca em questão o status quo da tradição moderna e sua fundamentação cientificista de que a produção de conhecimento se faz pela busca de purificação dos fatos, neutralidade e sustentação do lugar da verdade. sos vigentes se tornaram obsoletos (ROLNIK, 2007, p. 23).

Experimentamos outra qualidade na construção do relevo e da própria noção de território quando podemos ampliar nossa visão para além dos sentidos produzidos pela etologia, etnologia ou até mesmo a geografia. Neste sentido, Guattari e Rolnik (2005, p. 388) contribuem com essa ampliação quando nos indicam que

[...] o território pode ser relativo tanto a um espaço vivido, quanto a um sistema percebido no seio do qual um sujeito se sente "em casa". O território é sinônimo de apropriação, de subjetivação fechada sobre si mesma. Ele é o conjunto de projetos e representações nos quais vai desembocar, pragmaticamente, toda uma série de comportamentos, de investimentos, nos tempos e nos espaços sociais, culturais, estéticos, cognitivos.

A ampliação de nossa visão acerca da noção de território formulada por esses autores nos é preciosa, quando com ela já podemos falar de outro modo de operar com/ no território: acompanhar os contornos e arranjos da produção de territórios é estarmos atentos aos processos de territorialização e desterritorialização dos modos pelos quais construímos nossos modos de existência e nossas práticas. Neste sentido apostamos em um modo de fazer operado com/na prática cartográfica que em nada nos aparta dos nossos modos de produção de práticas de cuidado no território. Se entendermos que um território é fabricado por segmentações, por cortes e recortes, que parecem distintos entre si, mas que ao mesmo tempo, referenciam-se uns aos outros produzindo um sistema fechado em si mesmo, uma espécie de identidade; também sabemos que todo território tem a possibilidade de se desarrumar, de se desterritorializar. A possibilidade de desfazimento de territórios, as brechas que neles se fazem - quando estes já o são obsoletos para fazer passar os afetos que pedem expressão - podem também promover aberturas para a construção de outros jeitos de se relacionar, de se estar junto e de viver a vida.

O trabalho em saúde no/com/sobre o território e suas redes político-existenciais, locais, formais e/ou informais, requer uma atenção inclusiva ao que nele, através dele e por ele, pulsa na heterogeneidade de seus movimentos. Nesta compreensão, o território é, ao mesmo tempo, campo de formalizações de políticas extensivas que se querem universalizantes, científicas, programáticas, protocolares, normativas, redutoras de danos e riscos para o corpo orgânico, os sujeitos e seus modos de vida, indissociado de um plano intensivo que lhe é constituinte. O plano da vida como forças em constante processo de mutação, produção imanente nas surpresas das relações heterogêneas em meio as quais, nos diferentes encontros, a vida flui e "cava saídas em meio à proliferação de intoleráveis" (NEVES; MASSARO, 2009, p. 508).

Mergulharmos na processualidade da formação dos territórios, entendendo-os sempre como provisórios, requer que recusemos um suposto lugar "protegido" da neutralidade, apostando na mistura dos corpos, do caos que não se consegue classificar e controlar, nos riscos de inventar. Esta nos parece ser uma indicação importante, 
quando também percebemos que pensar o território na experiência de acompanhamento dos processos e práticas que o materializam, permite-nos experimentar uma problematização da própria prática clínica que nele e com ele somos convocados a operar.

\section{Ambiência: território de encontros}

Para a arquitetura dos espaços da saúde, a ambiência ${ }^{6}$ refere-se ao tratamento dado ao espaço físico entendido como espaço social, profissional e de relações interpessoais. Operar no território com o conceito de ambiência é então tomá-lo para além da composição técnica - simples e formal - dos ambientes e apreendê-lo em sua dimensão relacional. Neste sentido, pensar a construção de uma rede de cuidados de base territorial é implicar-nos com a produção do território em sua potência de constituir-se como território de encontros.

Ao pensarmos a feitura deste território, tal como afirmado acima, somos convocados à construção uma prática ética de cultivo da dimensão pública de todo processo de saúde quando então, afirmamos o público na inseparabilidade de três processos de produção: produção de saúde, produção de subjetividade e produção de territórios existenciais.

Se de algum modo, percebemos, no campo da atenção básica "um" certo delineamento do próprio território sanitário com seus princípios e diretrizes de territorialização, adscrição, longitudinalidade e planejamento ascendente; sabemos que estes não garantem por si só a construção de uma política pública compromissada com a produção da vida. Se as iniciativas para a constituição de um trabalho territorial têm sido apontadas na atenção básica como "modo de operar" o trabalho em saúde, entendemos que aqui, este modo se faz na contramão da normatização rígida dos processos de organização dos serviços de saúde que definem tanto modalidades de acesso e de cuidado centrados na doença, na queixa e nos especialismos quanto modos de trabalhar que destituem a capacidade de construção de autonomia e protagonismo dos trabalhadores e usuários. A ênfase no cuidado em saúde no território pressupõe um entendimento deste não apenas como espaço geofísico, mas, sobretudo como espaço cultural, relacional. Neste entendimento, o estabelecimento de vínculos e a criação de laços de compromisso e de corresponsabilidade entre profissionais da saúde e comunidade são pontos fundamentais para a ruptura da perspectiva tecnicista em saúde e o fortalecimento do envolvimento dos diversos atores sociais no processo de produção de cuidado em saúde.

De algum modo, o conceito de ambiência nos ajuda a pensar que é no cultivo de nossas relações, nas possibilidades de conexão com os fluxos heterogêneos do/ no território enquanto espaço vívido de complexidade e variabilidade da vida que inauguramos outros modos de agenciamento terapêutico, que produzimos "uma" outra relação entre território e clínica.

${ }^{6}$ Adotamos o conceito de Ambiência da Política Nacional de Humanização, como modo de ressignificar o que até então temos entendido como território sanitário.
Cabe-nos então interrogar sobre a clínica que se desdobra com/no território. O que afirmamos como clínica?

Passos e Barros (2003) e Lancetti (2006) nos ajudam a recolocar o problema da clínica, uma vez que, para instaurarmos processos disruptores com/nas práticas de cuidado orientando a organização dos serviços em busca de transformações para a saúde e para a vida das pessoas, temos como desafios não somente o enfrentamento de problemas concretos, como também a criação de novas questões. Desse modo, os autores nos fazem pensar que este duplo aspecto é, pois o que a clínica nos coloca.

De um lado, a clínica se apresenta como um campo de problemas a serem resolvidos exigindo um esforço intelectual de construção de estratégias de intervenção. De outro, ela se constitui como um plano problemático a ser criado exigindo o esforço intuitivo de desmontagem dos problemas estabelecidos e a invenção de novos problemas, de novos modos de existência (PASSOS; BARROS, 2003, p. 84).

Se não compreendemos a clínica como uma especialidade e sim como uma experiência podemos então recolocar o problema da clínica perguntando-nos conforme os autores mencionados "o que pode a clínica?" ou o que nela se passa. O que se passa na experiência do acompanhamento? Compreendermos a clínica como uma experiência, traz à cena o paradoxo de ela mesmo ser confrontada em sua prática com a dimensão de não-clínica. De algum modo, é nesta zona de indiscernibilidade onde saberes e objetos são inseparáveis que o exercício clínico se faz, trabalhando nas formas, nos seus índices ativos, intensificando as aberturas e produzindo-as em muitos momentos. Eis aí o que denominamos, anteriormente, de dimensão intercessora.

Forçando sempre os seus limites ou operando no limite, a clínica se apresenta como uma experiência do entre-dois que não pode se realizar senão neste plano onde os domínios do eu e do outro, do si e do mundo, do clínico e do não clínico se transversalizam. (BARROS; PASSOS, 2004, p. 279).

A construção de uma outra postura neste exercício clínico nos é exigida quando já não bastam mais os recortes binarizantes e excludentes operados pelo paradigma da ciência moderna que simplifica os problemas numa ação purificadora e deputariva. Colocamos então o desafio de superarmos os antigos isolamentos entre as disciplinas/ saberes produzindo um atravessamento dos mesmos, não em seu interior, mas entre eles. Somos forçados a pensar a complexidade como o problema das fronteiras dos objetos e dos saberes.

Esta complexidade comparece na experiência limiar dos modos de se operar na atenção básica quando percebemos que a clínica no território se exerce em uma condição minoritária. Fora dos espaços fechados de reclusão e fora de uma lógica manicomial que força os limites identitários das disciplinas e saberes, vivemos uma experiência preciosa de deslocalização de uma suposta clínica objetivada, garantida pela previsibilidade dos saberes e resguardada por quatro paredes. A experiência de acompanhamento vivida marca-se, muito mais, pelos percursos do caminhar do que pelos lugares de partida ou de 
chegada. Atenta às articulações com o fora, às conexões possíveis e aos planos de consistência que se conquistam, estas nos parecem ser as pistas para viver este processo de experimentação e acompanhamento que é sempre de aprendizagem. A clínica trabalha com essa experiência de produção, sendo ela mesma produtora. Trabalha em um plano de encontro, plano de produção da vida, no entre-dois, fazendo-se ela mesma como potencializadora de novos encontros.

Muitas vezes confundimos a condição minoritária com a qual nos encontramos nesta experiência com uma condição de menoridade, de uma "clínica inferior", e com isto endurecemos nas passagens que essa experiência pode operar buscando um saber supostamente capaz de emprestar-nos uma identidade.

Para Deleuze e Guattari (1997a) uma maioria é sempre numerável e supõe um estado de dominação. A minoria, por sua vez, se define como um conjunto não numerável, independente do número dos seus elementos. A minoria faz valer a potência do inumerável, que não se mede por sua capacidade de se impor no sistema majoritário, mas justamente de fazer valer uma força dos conjuntos não numeráveis. Ela é a fórmula das multiplicidades, é devir de todo o mundo (DELEUZE; GUATTARI, 1997b). "No entanto, é preciso não confundir 'minoritário' enquanto devir ou processo, e "minoria' como conjunto ou estado" (DELEUZE; GUATTARI, 1997a, p. 88). O minoritário diz daquilo que foge ao padrão dominante do socius: "todo devir é um devir minoritário" (DELEUZE; GUATTARI, 1997a, p. 87).

Há que estarmos aqui, atentos a este mal-estar da minoridade e uma desatenção com o que esse modus operandi tem de devir-minoritário: constituir-se numa operação de desinstitucionalização da própria clínica. Pensar uma micropolítica ativa e viva nos processos de constituição do cuidado requer de nós uma reversão desta condição de minoridade para uma potência minoritária. Sobretudo, nos enseja a pensar nos modos como temos tomado as forças destes movimentos reinventivos na construção de práticas de cuidado na interface Saúde Mental e Atenção Básica.

Por certo, podemos pensar nesta intercessão, no campo da saúde, na construção de práticas de cuidado que assegurem a importância do incremento dos laços sociais, o aumento de autonomia, e contratualidade "daqueles que cuidamos". Entretanto, podemos também pensar que, quando lutamos contra os processos de exclusão social, de isolamento afetivo e da impossibilidade de se construir protagonismos na vida, há também que se romper com certa dicotomia no campo das práticas de saúde, daqueles que cuidam e daqueles que são cuidados. De algum modo, podemos dizer que também precisamos construir um cuidado dos próprios processos e práticas de trabalho que pomos a funcionar em nosso cotidiano. Estaríamos então apontando não somente para um cuidado do cuidado, mas, sobretudo, para um cuidado da dimensão relacional na qual nos constituímos.

Fractal, Rev. Psicol., v. 29 - n. 1, p. 24-33, 2017
Construirmos práticas de cuidado que cultivem a vida em sua expansão, em sua capacidade de produzir protagonismo, autonomia e reinvenção de si mesma, em nada nos aparta do modo como temos tomado e operado no/ com o território.

\section{Considerações Finais}

De algum modo, o encontro Saúde Mental e Atenção Básica com seu plano de tessitura com/no território chama-nos atenção justamente pelo movimento transversal que opera, ao entrecruzar as mais variadas interfaces políticas, econômicas, sociais, culturais, sexuais, etc., desestabilizando os limites identitários das disciplinas e produzindo diferenciações no próprio conceito de clínica. Neste sentido podemos operar uma problematização do paradigma racionalista baseado no binômio problema-solução/causa-efeito quando experimentamos a construção de uma ação no território que se afirma muito mais na força das próprias experiências e nos efeitos terapêuticos que produzem. Cabe-nos, pois, pensarmos em uma prática ética de produção de cuidado no território que se efetiva e se sustenta afetivamente com/na tessitura de redes instituintes aquecidas no/pelos encontros-agenciamentos que fazemos.

Como nos alerta Passos e Barros, 2003, não perdemos com isso a preocupação com as questões estratégias, mas estas não se definem mais como puramente técnicas. Uma dimensão do fazer muito "menos como inventário de procedimentos e formas de ação e mais como um processo constante de invenção de estratégias de intervenção em sintonia com os novos problemas constituídos" (PASSOS; BARROS, 2003, p. 85).

A constituição de um modelo assistencial que subverta a lógica e o paradigma biomédico, tanto por parte da Atenção Básica, com a Estratégia de Saúde da Família, quanto por parte da Saúde Mental (inserida com essa portaria nos NASF'S $)^{7}$ deve ser interrogada continuamente quanto a seus efeitos. Pois, é fundamental estarmos atentos para que a intenção de mudança destes paradigmas não se resuma a expansão de "ambulatórios melhorados", riscos concernentes tanto às práticas de saúde mental como a própria proposta do PSF. Como nos sinaliza Silva Júnior et al. (2006, p. 64) “[...] sob o nome de programa de saúde da família encontram-se desde as piores práticas de pronto atendimento simplificado, passando por atendimento médico tradicional, até experiências realmente inovadoras na assistência”.

Afirmarmos o protagonismo da ação no território, comporta para nós, o desafio de questionarmos e reinventarmos o modo de organização do sistema de saúde e sua lógica de processo de trabalho, apostando no aquecimento das redes instituídas no campo da saúde, naquilo que nelas e através delas produz movimentos instituintes de expansão e afirmação da vida.

${ }^{7} \mathrm{Em} 2008$, com a Portaria n ${ }^{\circ} 154$, há o estabelecimento formal de uma política de financiamento com a criação dos Núcleos de Apoio à Saúde da Família/NASF (BRASIL, 2008). Como modo de ampliar a abrangência e o escopo das ações de atenção básica melhorando a qualidade e a resolutividade da atenção à saúde, o NASF constitui-se por equipes compostas por profissionais de diferentes áreas de conhecimento que atuarão em parceria com os profissionais das equipes de Saúde da Família. 
Como então pensarmos a produção desta interface Saúde Mental e Atenção Básica? Como construí-la em aliança com as forças dos movimentos instituintes produzidos neste encontro? De algum modo, acreditamos que mais do que a produção de respostas para nossas questões há que se estar atento para os novos problemas que temos construído em nossa prática cotidiana.

$\mathrm{Na}$ experimentação dos encontros gerados com/no território produzimos pistas para o enfrentamento dos desafios que temos vivido no campo da saúde, quando também, reconhecemos a necessidade de indagarmos e apoiarmos a existência de outras redes que se constituem cotidianamente para além e aquém do campo da saúde. Redes afetivas de solidariedade e partilha que sustentam a produção de "uma"8 vida no território como potência de ação, reinvenção e luta frente aos processos de exclusão, miséria e abandono produzidos pelo capitalismo, e contra os quais também estamos em constante enfrentamento quando pensamos na produção de práticas de saúde que se façam na contramão dos processos de privatização da vida, de autoritarismo e violação dos direitos humanos.

\section{Referências}

ALVAREZ, J.; PASSOS, E. Cartografar é habitar um território existencial. In: PASSOS, E.; KASTRUP, V.; ESCÓSSIA, L. (Org.). Pistas do método cartográfico. Porto Alegre: Sulina, 2009. p. 131-149.

BARROS, R. D. B.; PASSOS, E. O que pode a clínica? A posição de um problema e de um paradoxo. In: FONSECA, T. M. G.; ENGELMSN, S. (Org.). Corpo, arte e clínica. Porto Alegre: Sulina, 2004. v. 1., p. 275-286.

BARROS, R. D. B.; PASSOS, E. Humanização da saúde: um novo modismo? Interface - Comunicação, Saúde, Educação, Rio de Janeiro, v. 9, n. 17, p. 389-406, 2005.

BRASIL. Ministério da Saúde. Política Nacional de Atenção Básica. Portaria $n^{\circ} 154$, de 24 de janeiro de 2008. Criação e orientação para a implantação dos Núcleos de Apoio à Saúde da Família NASF. Brasília: Ministério da Saúde, 2008.

CAMPOS, F. C. B.; NASCIMENTO, S. P. S. O apoio matricial: reciclando a saúde mental na atenção básica. Cadernos IPUB: $\mathrm{n}^{\circ}$ 24. Saúde mental na atenção básica. Rio de Janeiro: UFRJ/ IPUB, 2007. p. 91-100.

CAMPOS, G. W. S. Subjetividade e administração de pessoal: considerações sobre modos de gerenciar o trabalho em equipes de saúde. In: MERHY, E.; ONOCKO, R. (Org.). Agir em saúde: um desafio para o público. São Paulo: Hucitec, 1997. p. 229266.

CAMPOS, G. W. S.; GUERRERO, A. (Org.). Manual de práticas de atenção básica: saúde ampliada e compartilhada. São Paulo: Aderaldo \& Rothschild; 2010.

DELEUZE, G. A imanência: uma vida. In: VASCONCELLOS, J; FRAGOSO, M. A. da R. (Org.). Gilles Deleuze, imagens de um filósofo da imanência. Londrina: UEL, 1997. p. 15-19.

\footnotetext{
${ }^{8}$ Deleuze (1997) radicaliza a idéia de vida, afirmando-a paradoxalmente como 'uma vida' que não encontra referência em uma pessoa ou em um fato que a transcende, mas em si mesma como potência singular de ação e reinvenção. $\mathrm{O}$ autor marca a importância do uso do artigo indefinido 'uma vida', numericamente uma, mas multiplicidade substantiva afirmando-a em seu processo de conectividade intempestiva, em constante estado de criação e recriação.
}

DELEUZE, G.; GUATTARI, F. Introdução: Rizoma. In: Mil platôs: capitalismo e esquizofrenia. São Paulo: Ed. 34, 1995. v. 1, p.10-36.

DELEUZE, G.; GUATTARI, F. 10.1730 Devir-intenso, deviranimal, devir-imperceptível. In:__. Mil platôs: capitalismo e esquizofrenia. São Paulo: Ed. $\overline{34,1997 a, ~ v . ~ 4, ~ p . ~ 11-114 . ~}$

DELEUZE, G.; GUATTARI, F. Aparelho de captura. In: Mil platôs: capitalismo e esquizofrenia. São Paulo: Ed. 34, 1997b. v. 5, p. 111-178.

DELEUZE, G. Conversações. São Paulo: Ed. 34, 1992.

FIGUEIREDO, M. D. Saúde Mental na Atenção Básica: um estudo hermenêutico-narrativo sobre o Apoio Matricial na rede SUS-Campinas (SP). 2006. Dissertação (Mestrado em Saúde Coletiva)-Universidade Estadual de Campinas, Campinas, 2006.

GIRARDI G. Aventuras da leitura de mapas. In: SEEMANN, J. (Org.). A aventura cartográfica: perspectivas, pesquisas e reflexões sobre a cartografia humana. Fortaleza: Expressão, 2006. v. 1, p. 61-72.

GUATTARI, F. Caosmose. Rio de Janeiro: Ed. 34,1992.

GUATTARI F. Transversalidade. In: __ Revolução molecular: pulsações políticas do desejo. São Paulo: Brasiliense, 1981. p. 88-105.

GUATTARI F.; ROLNIK, S. Micropolítica: cartografia do desejo. Petrópolis, RJ: Vozes, 2005.

HAESBAERT, R. Território e multiterritorialidade: um debate. GEOgrafia, ano IX, n. 17, p. 19-45, 2007.

LANCETTI, A. Clínica peripatética. São Paulo: Hucitec, 2006.

LANCETTI, A.; AMARANTE, P. Saúde Mental e Saúde Coletiva. In: CAMPOS, G. W. S. et al. (Org.). Tratado de Saúde Coletiva. São Paulo: Hucitec, 2006. p. 615-634.

MACERATA, I.; SOARES, J. G. N.; RAMOS, J. F. C. Apoio como cuidado de territórios existenciais: Atencão Básica e Rua. Interface (Botucatu), Botucatu, v. 18, supl. 1, p. 919-930, 2014. Cross ${ }^{\text {Ref. }}$

MOTA, A; SCHRAIBER, L. B. Atenção primária no sistema de saúde: debates paulistas numa perspectiva histórica. Saúde Sociedade, São Paulo, v. 20, n. 4, p. 837-852, 2011. Cross ${ }^{\text {Ref. }}$

NEVES C. A. B. Manual de práticas da atenção básica: saúde ampliada e compartilhada. Cad. Saúde Pública, Rio de Janeiro, v. 27, n. 4, abr. 2011. Cross ${ }^{\text {Ref. }}$

NEVES, C. A. B.; MASSARO, A. Biopolítica, produção de saúde e um outro humanismo. Interface (Botucatu), Botucatu, v. 13, supl. 1, p. 503-514, 2009. Cross ${ }^{\text {Ref. }}$

NICÁCIO, F.; KINKER, F. S. O desafio do viver fora: construindo a cooperativa paratodos. In: CAMPOS, F; HENRIQUES, C. (Org.). Contra a maré à beira mar: a experiência do SUS em Santos. São Paulo: Scritta, 1996. p. 121-131.

PAIM, J. S. Saúde, politica e reforma sanitária. Salvador: ISC, 2002.

PAIM, J. S. Atenção Primária à Saúde: uma receita para todas as estações? Saúde em Debate, Rio de Janeiro, v. 36, n. 94, p. 343-347, jul./set. 2012. Cross ${ }^{\text {Ref. }}$

Fractal, Rev. Psicol., v. 29 - n. 1, p. 24-33, 2017 
PASCHE, D. F. Contribuições da política de humanização da saúde para o fortalecimento da atenção básica. In: BRASIL. Ministério da Saúde. Secretaria de Atenção à Saúde. Política Nacional de Humanização. Cadernos HumanizaSUS. Brasília: Ministério da Saúde, 2010. v. 2, p. 11-28. Disponível em: $<$ http://bvsms.saude.gov.br/bvs/publicacoes/cadernos humanizasus atencao_basica.pdf $>$. Acesso em: 22 out. 2014.

PASSOS, E.; BARROS, R. D. B. Complexidade, transdisciplinaridade e produção de subjetividade. In: FONSECA, T M G.; KIRST, P. Cartografias e devires: a construção do presente. Porto Alegre: UFRGS, 2003. p. 81-89.

PERLONGHER, N. Territórios marginais. In: BARENBLITT, G. (Ed.). SaúdeLoucura: Grupos e Coletivos. São Paulo: Hucitec, 1993. v. 4, p. 46-69.

ROLNIK, S. Cartografia sentimental: transformações contemporâneas do desejo. Porto Alegre: Sulina, UFRGS, 2007.

SANTOS, M. A natureza do espaço: técnica e tempo/razão e emoção. São Paulo: Hucitec, 1996.

SANTOS, M. Metamorfoses do espaço habitado: fundamentos teóricos e metodológicos da Geografia. São Paulo: USP, 2008.

SILVA JÚNIOR, A. G. et al. Avaliação de redes de atenção à saúde: contribuições da integralidade. In: PINHEIRO, R.; MATTOS, R. A. de. (Org.). Gestão de redes: práticas de avaliação, formação e participação na saúde. Rio de Janeiro: CEPESC, 2006. p.61-90.

TESTA, M. Pensar em saúde. Rio de Janeiro: Abrasco, 1992.

VIEIRA S. S. Saúde Mental e Atenção Básica: o cuidado como criação de cantos no território. 2009. Dissertação (Mestrado em Psicologia)-Universidade Federal Fluminense, Niterói, 2009.

Recebido em: 26 de novembro de 2014 Aceito em: 23 de maio de 2015 